\title{
What are the usage dimensions of open?
}

OSI 2016: Final Presentation 


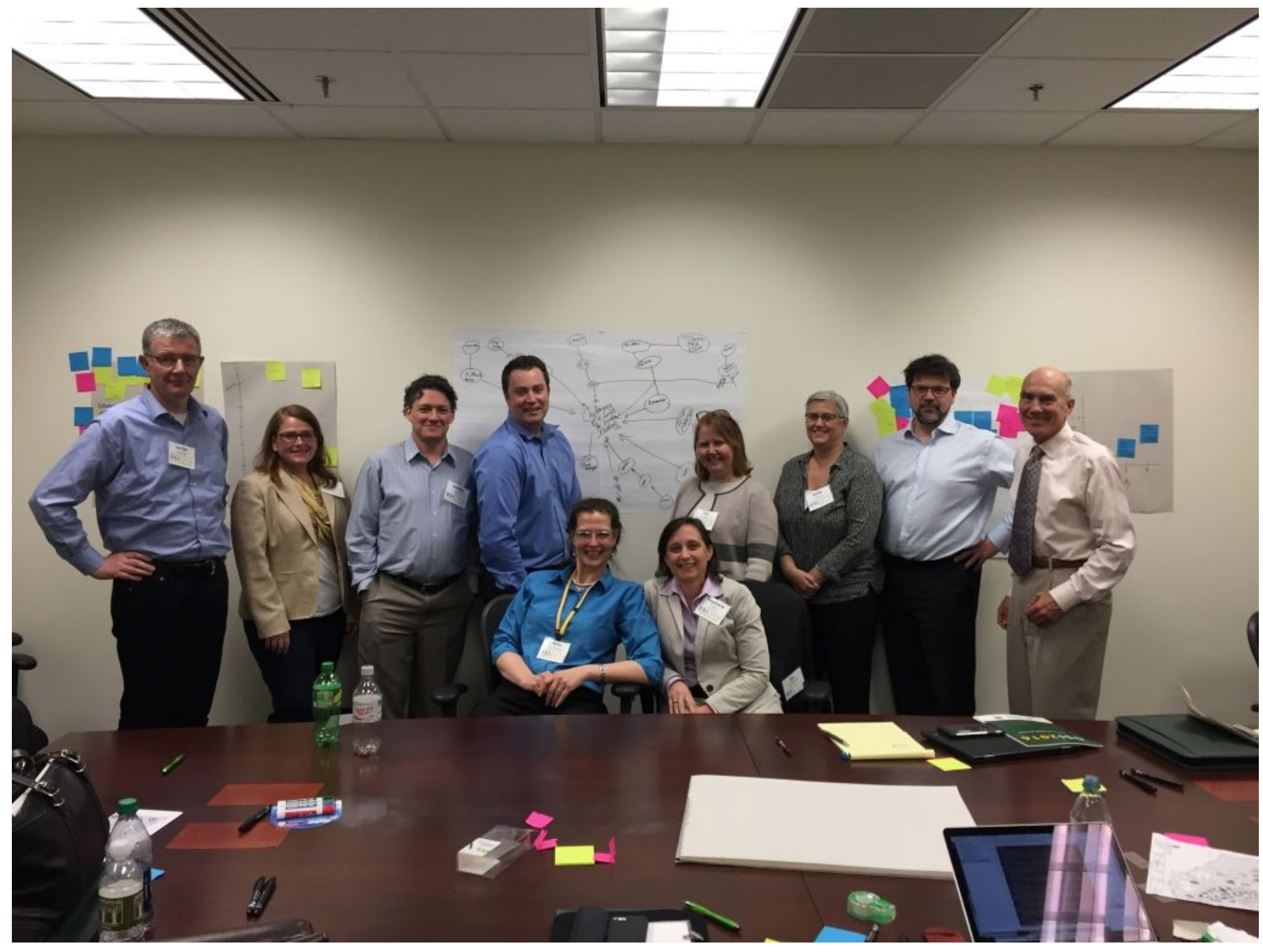

The team 
Identified Areas of Priority

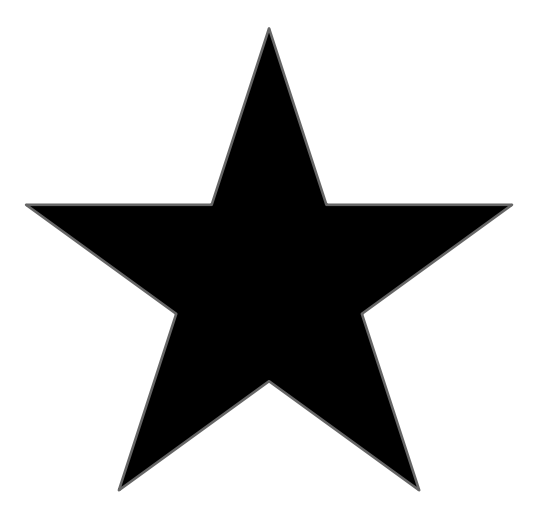

Character of Outputs \&

Research workflow

Flexible economics 


\section{- Researchers \&}

Librarians

- Funders

Stakeholders

- Service Providers

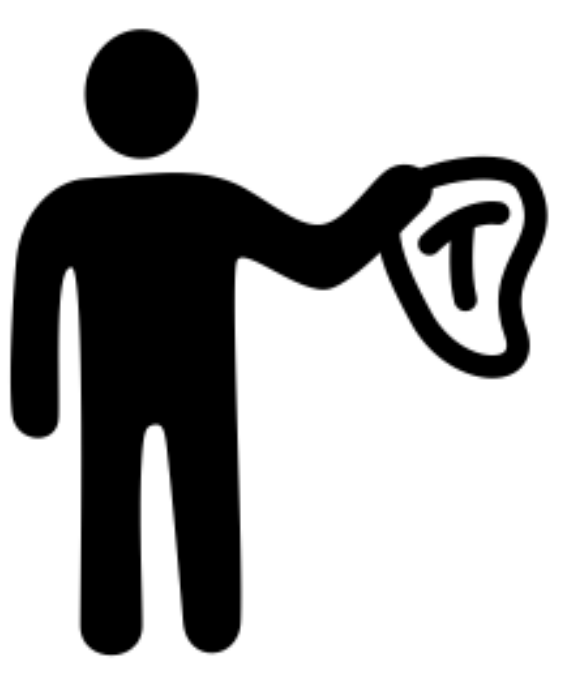

- Public 

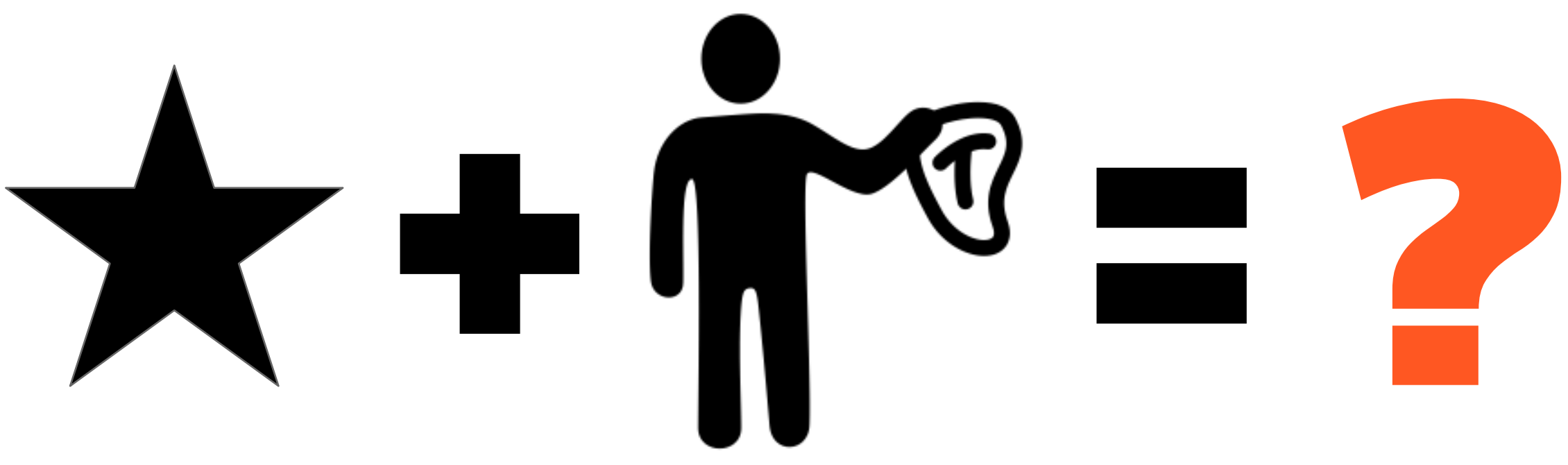


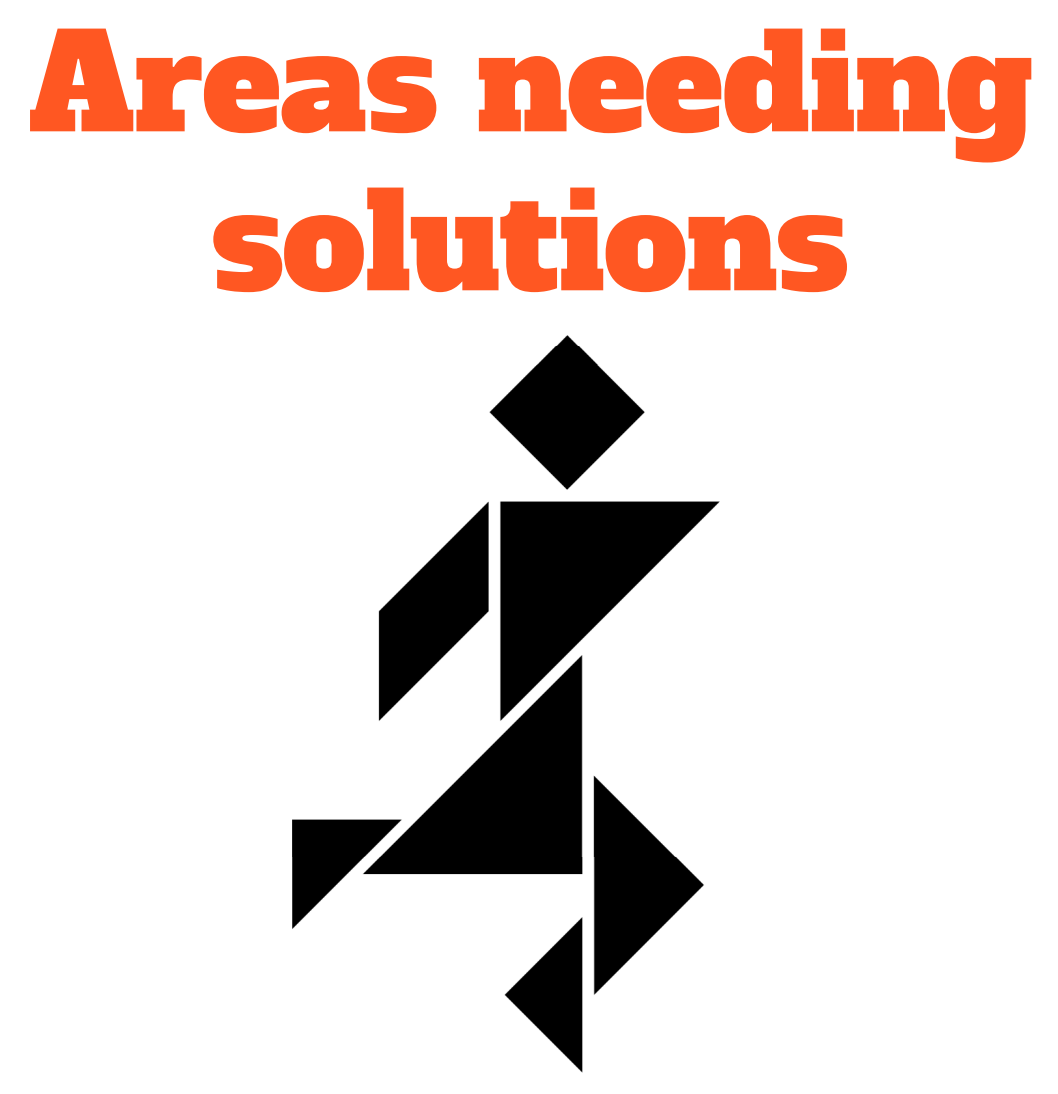

Standards and norms

Exit strategies

Incentive systems

Inertia balanced with the desire for change while maintaining continuity 


\section{A working group of major funders to:}

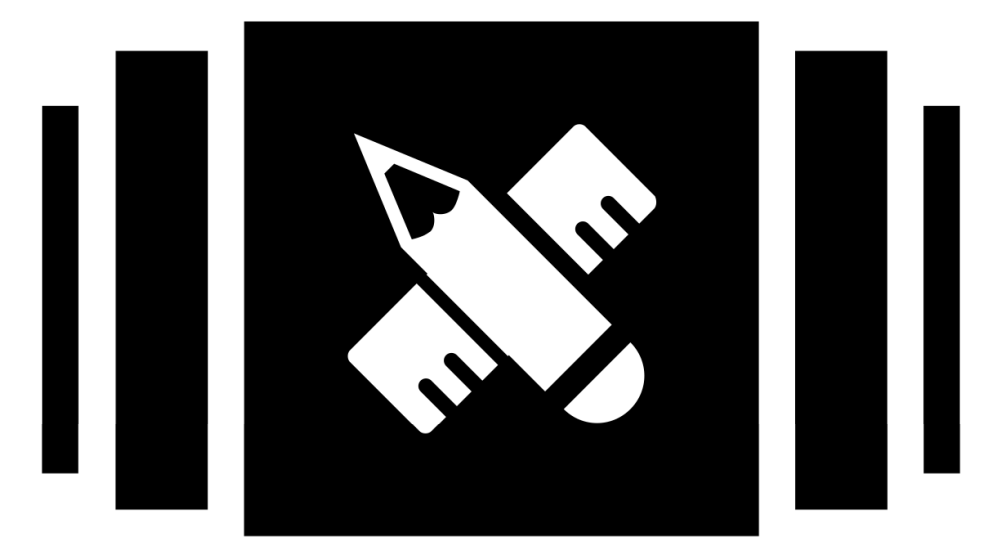

Facilitate budgeting to support OA.

Use workflow tools e.g. ORCID

$*$

* Someone (Force11?) take up the creation of 1pager that speaks to these issues to funders? 


\section{Intelligent partnerships}

To make things easier for researchers

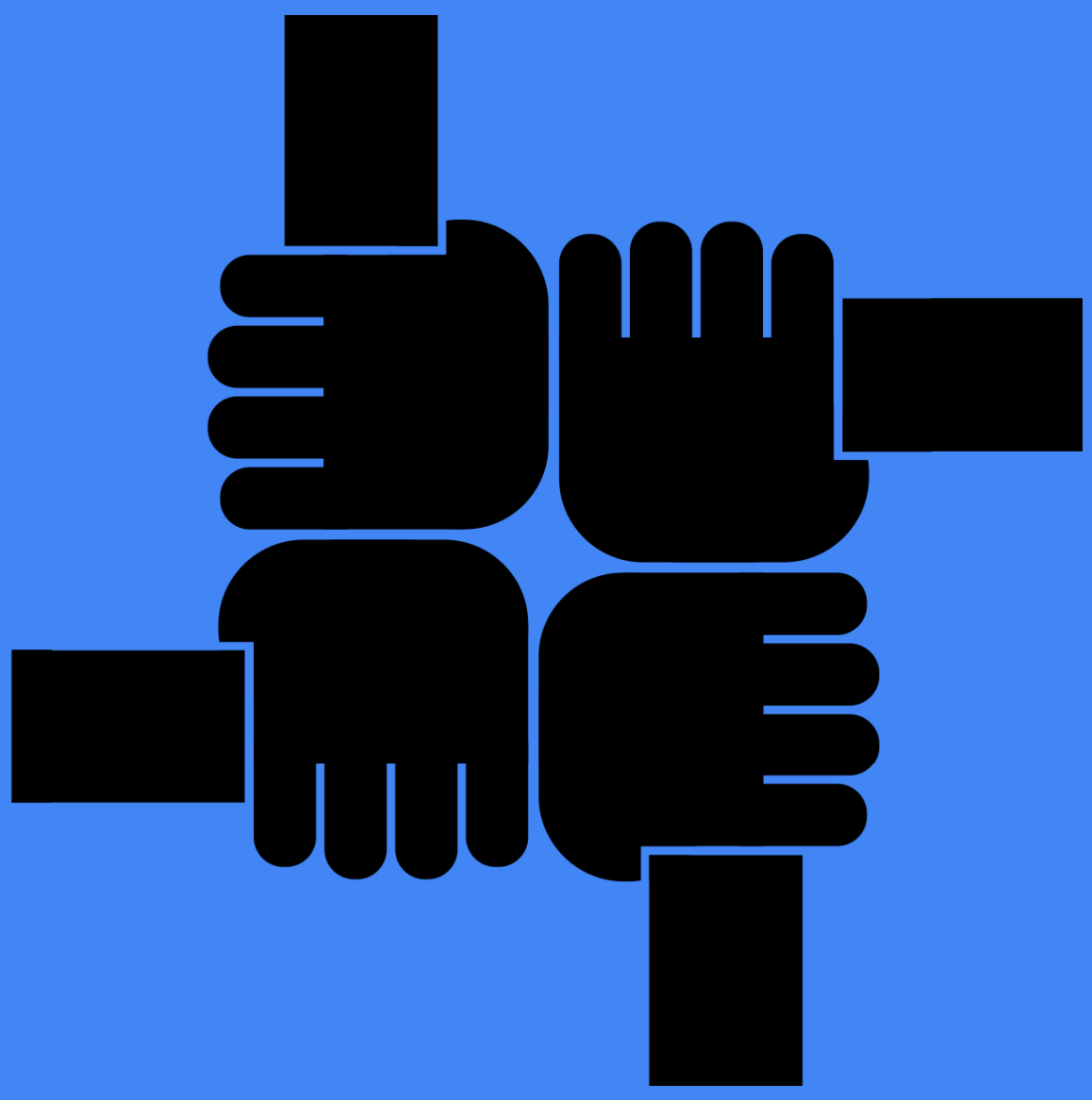


Landscape assessment for current best practices, standards, norms

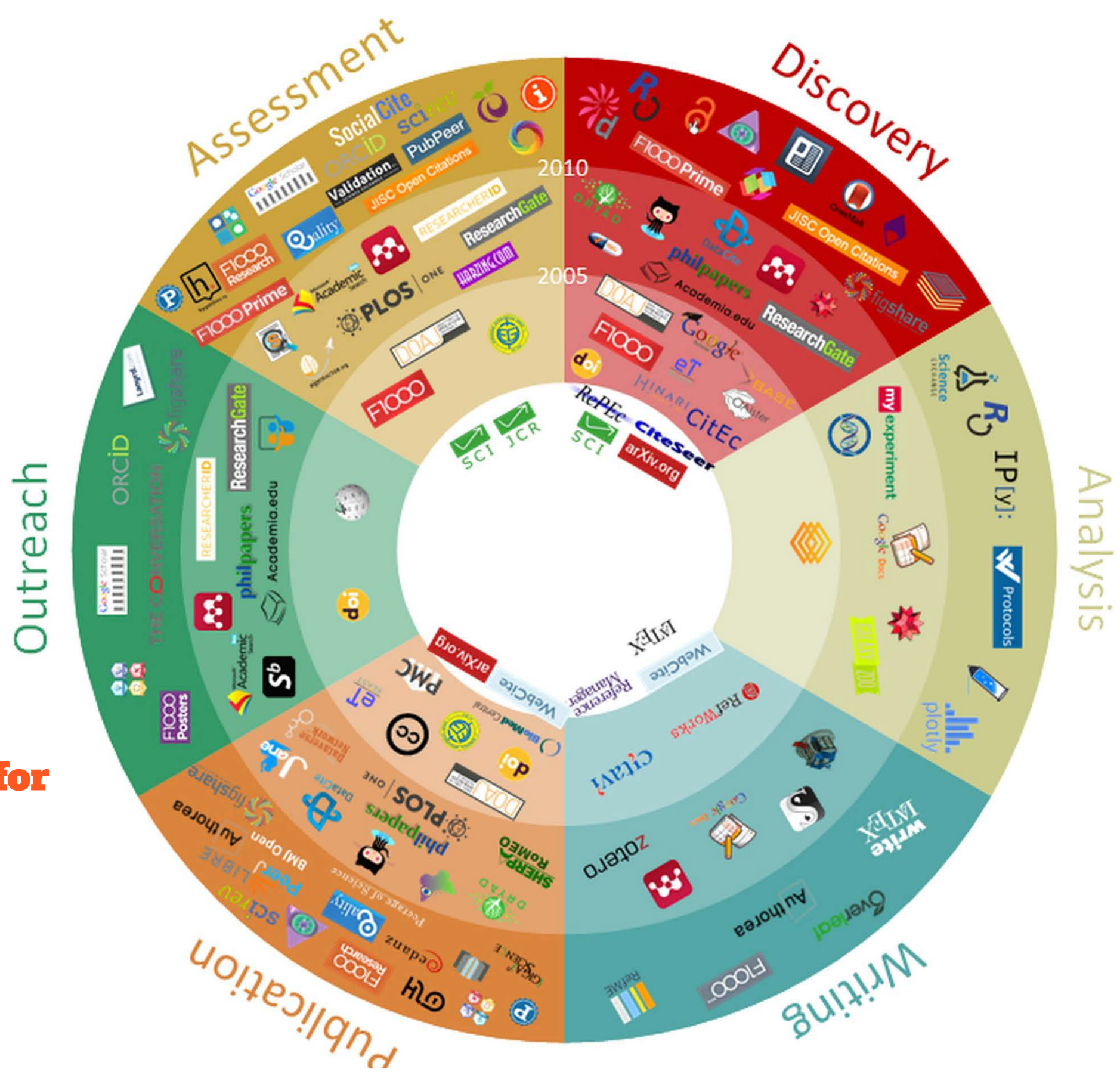




\section{Propose an idea workshop}

in the area of exit strategies/ sustainability to develop project solicitations

\section{Bxit strategies}

a means of leaving one's current situation with a path to sustainability through considering appropriate governance

\section{Industry involvement in} \#OSI2017: Google, Microsoft, Amazon

Use available resources: JISC, JSTor, Ithaka 


\section{Fducating sustainers}

Inclusion of \#OpenResearch in disciplinary curricula Funder teaching/training grants (e.g., NIH BEST) Get AAU \& APLU \& AAMC in on the game of open

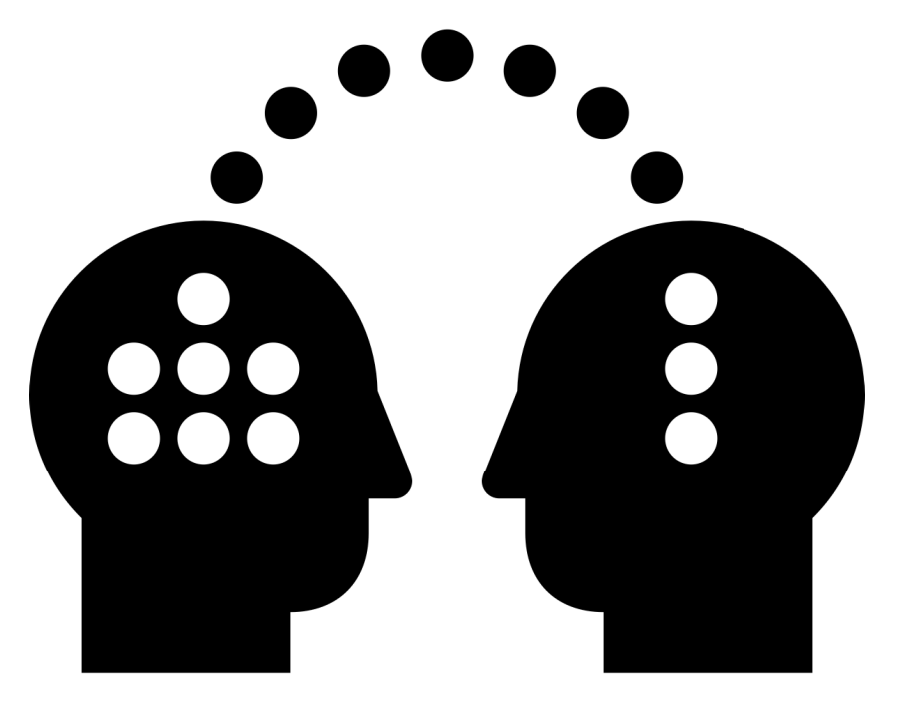
scholarship: Thoughts, concerns, opportunities for change. 


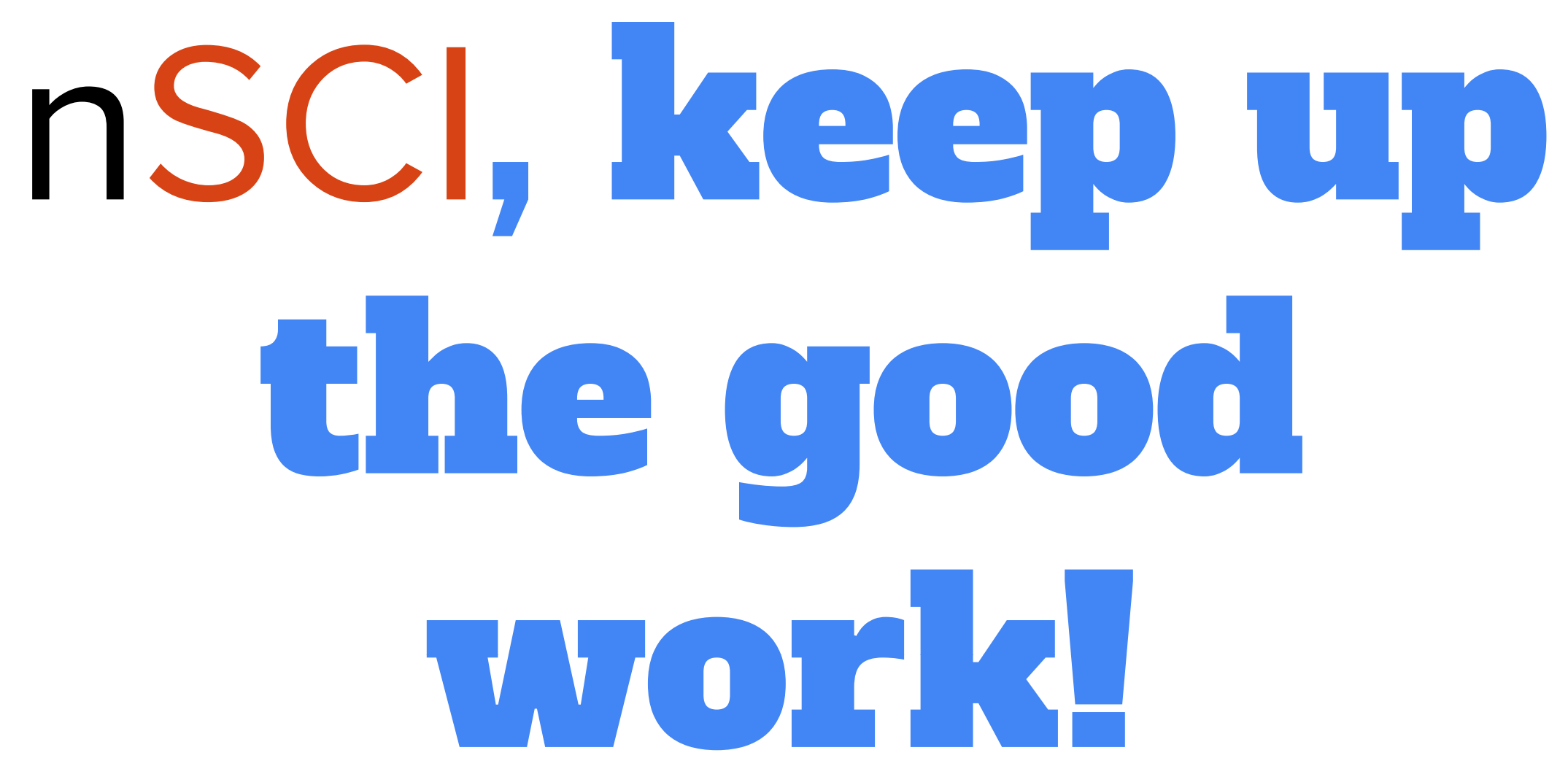




\section{References}

- 101 Innovations in Scholarly Communications: https: //innoscholcomm.silk.co/

- Association of American Universities: http://www.aau.edu/

- Association of Public \& Land-Grant Universities: http: //www.aplu.org/

- Association of American Medical Colleges: https://www. aamc.org/

- Broadening Experiences in Scientific Training: http://www. nihbest.org/

- Jisc: https://www.jisc.ac.uk/

- JSTOR: http://www.jstor.org/

- ITHAKA: http://www.ithaka.org/

- nSCl: http://nationalscience.org/ 
The most contentious debate in our workgroup was whether this should live or die \#OSI2016 ${ }^{\circ}$

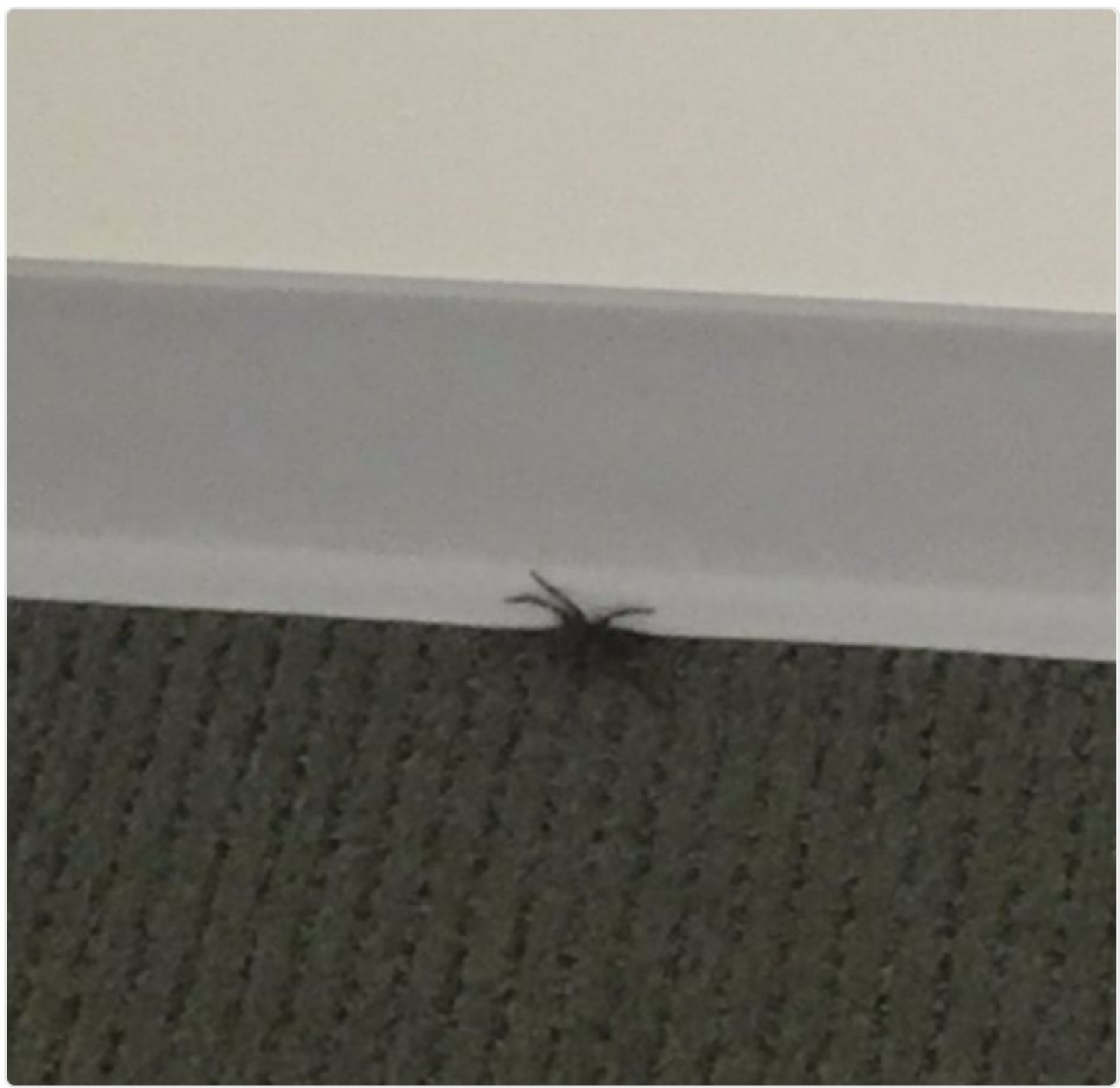




\section{References}

- 101 Innovations in Scholarly Communications: https: //innoscholcomm.silk.co/

- Association of American Universities: http://www.aau.edu/

- Association of Public \& Land-Grant Universities: http: //www.aplu.org/

- Association of American Medical Colleges: https://www. aamc.org/

- Broadening Experiences in Scientific Training: http://www. nihbest.org/

- Jisc: https://www.jisc.ac.uk/

- JSTOR: http://www.jstor.org/

- ITHAKA: http://www.ithaka.org/

- nSCl: http://nationalscience.org/ 
The most contentious debate in our workgroup was whether this should live or die \#OSI2016 ${ }^{\circ}$

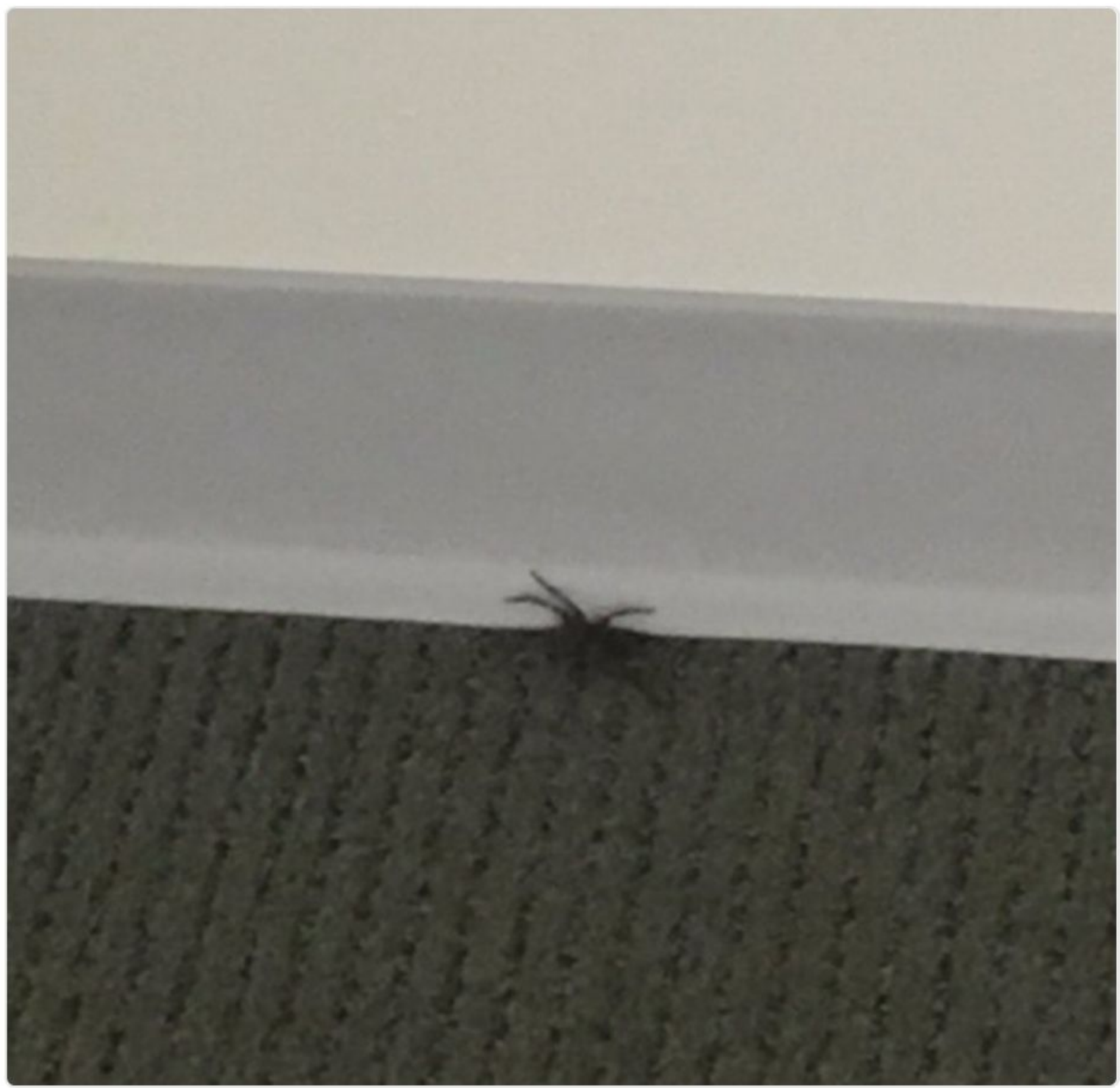

